\title{
ANNULAR FLOW ENTRAINMENT RATE EXPERIMENT IN A VERTICAL PIPE
}

Martin A. Lopez de Bertodano

Cheng-Shiun Jan

Stephen G. Beus
RECEIVED

JUพ 03 ใด96

OSTI

DE-AC11-93PN38195

\section{NOTICE}

This report was prepared as an account of work sponsored by the United States Government Neither the United States, nor the United States Department of Energy, nor any of their employees, nor any of their contractors, subcontractors, or their employees, makes any warranty, express or implied, or assumes any legal liability or responsibility for the accuracy, completeness or usefulness of any information, apparatus, product or process disclosed, or represents that its use would not infringe privately owned rights.

Operated for the U.S. Department of Energy by WESTINGHOUSE ELECTRIC CORPORATION

DISTRIBUTION OF THIS DOCUMENT IS UNLAMTES 


\title{
Annular Flow Entrainment Rate Experiment in a Vertical Pipe
}

\author{
Martin A. Lopez de Bertodano and Cheng-Shiun Jan \\ School of Nuclear Engineering \\ Purdue University \\ West Lafayette, IN \$7907-1290 \\ and \\ Stephen G. Beus \\ Bettis A tomic Power Laboratory \\ Westinghouse Electric Corporation \\ West Mimin, PA 15122-0079
}

\begin{abstract}
An air-water experiment has been performed to measure the entrainment rate in a small pipe. The current data extend the available database in the literature to higher gas and liquid flows and also to higher pressures. The ranges covered are $8.1 \times 10^{2} \mathrm{~kg} / \mathrm{m}^{2} \mathrm{~s}<\rho_{\mathrm{gg}}{ }^{2}<4.5 \times 10^{4} \mathrm{~kg} / \mathrm{m}^{2} \mathrm{~s}, \quad 5.5$ $\mathrm{kg} / \mathrm{m}^{2} \mathrm{~s}<\rho_{j_{\mathrm{f}}}^{2}<2.9 \times 10^{2} \mathrm{~kg} / \mathrm{m}^{2} \mathrm{~s}$ and $140 \mathrm{kPa}<\mathrm{p}<660 \mathrm{kPa}$.

The test section has an internal diameter of $9.5 \mathrm{~mm}$. and an LD ratio of 440 . The measurements were made by extracting the liquid film at two locations establishing fully developed annular flow. The data were validated by visual observation and comparisons with the data of Cousins and Hewitt(2).

A mechanism for the entrainment rate in terms of Taylor's ripple instability is proposed. The theory is modified to include the effect of the inertia of the droplets in the gas stream. The model results in a dimensionless group that includes the Weber number based on the droplet concentration and the liquid film Reynolds number. Kataoka and Ishii's correlation (1982) is modified in light of this model and the new correlation scales the present data and Cousins and Hewitt's data very well.
\end{abstract}

\section{Nomenclature:}

D tube diameter (m)

d deposition rate $\left(\mathrm{kg} / \mathrm{m}^{2} \mathrm{~s}\right)$

E entrainment fraction

$E_{\infty} \quad$ equilibrium entrainment fraction

jf volumetric flux of total liquid $(\mathrm{m} / \mathrm{s})$

$\mathrm{j}_{\mathrm{g}} \quad$ volumetric flux of gas (m/s)

$k$ wave number

$k_{A} \quad$ entrainment coefficient $\left(s^{2} / \mathrm{kg}\right)$

L length of test section (m)

m film thickness (m)

$\mathrm{P}$ tube perimeter (m)

$\mathrm{P} \quad$ pressure $(\mathrm{kPa})$

$\mathrm{Re}_{\mathrm{f}}$ Reynolds number of the liquid

$R_{\text {ff }}$ Reynolds number of the liquid film

$\mathrm{Re}_{\mathrm{Ifc}}$ critical film Reynolds number

$\mathrm{T}$ temperature $\left({ }^{\circ} \mathrm{C}\right)$

$t$ time (s)

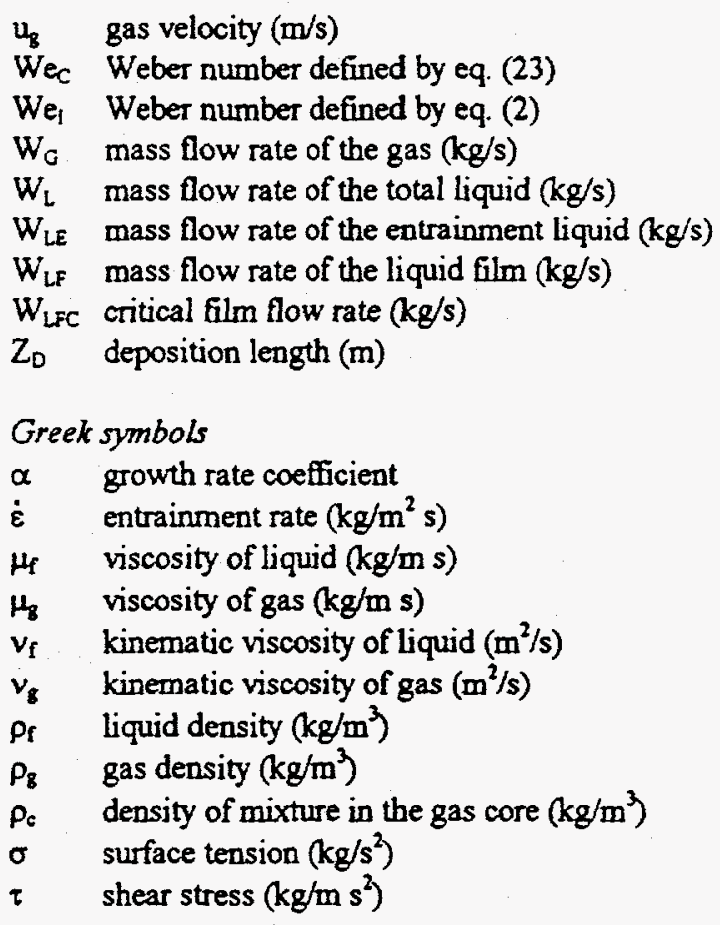

\section{Introduction}

Reliable two-fluid simulation of annular flow and critical heat flux due to film dryout requires credible models for such hydrodynamic phenomena as droplet entrainment and deposition and interfacial shear. In air-water experiments, or other adiabatic annular flow tests, it is desirable to promote the rapid establishment of annular flow at the inlet. The gas core and liquid film are typically introduced so as to encourage liquid to attach to the walls except as entrained by the vapor core. The most common mode of annular flow introduction is to begin with pure gas flowing in the test section, then introduce the liquid through a porous segment of the test section wall. The gas and liquid flow rates are set such as to warrant the expectation of annular flow based on flow regime maps. This technique is described in Cousins and Hewitt (1968), Okada and Fujita (1993), Andreussi et. al. (1982), Azzopardi (1985), Azzopardi et. al. (1991), Keeys et. 
al. (1970), Sekoguchi et. al. (1985) and Govan et. al. (1989), where the methodology has been proven successful for low liquid flow rates. Reported tests have been limited to test sections of small diameters ( 12 to $40 \mathrm{~mm}$.) where the liquid flow rates are less than $7.6 \times 10^{-4} \mathrm{~m}^{3} / \mathrm{s}$.

Entrainment rates are typically determined through double extraction of the liquid film in the following manner. Annular two-phase flow is established and a development length is provided to permit equilibrium conditions to be achieved, i.e. until deposition and entrainment rates become equal and the liquid film stabilizes. The liquid film is then extracted through a porous wall section, after which a deposition length of test section is provided where drops accurmulate on the wall and the film is redeveloped under conditions such that no entrainment takes place. The second film is extracted through another porous wall section. The flow rate of the two extracted streams is measured. The first flow rate is a measure of the fluid film flow rate from which the entrainment fraction can be inferred. The second flow rate gives the deposition rate at equilibrium, which is assumed to be equal to the entrainment rate.

\section{Air-Water Loop}

The comprehensive measurements included temperature (T), pressure at the injection $\left(P_{i n}\right)$, pressure in the separator tank $\left(P_{5 y}\right)$, water flow rate at the injection $\left(W_{L}\right)$, air flow rate at the injection $\left(W_{G}\right)$, pressure drop $(d p / d z)$, film thickness (m), extracted water flow rate from the first and second extraction units $\left(W_{L F}, W_{L F}\right)$, and extracted air flow rate from the first and second extraction units $\left(W_{G 1}, W_{G_{2}}\right)$. The methods used for measurements and calibrations are discussed in some detail below.

\subsection{Experimental Loop}

All the experiments were carried out with an adiabatic upwards air-water loop. The frame used to support the instruments and test section was constructed with steel unistrut channels. A laser beam was used to make sure that the test section was aligned. The test section is made of a $9.5 \mathrm{~mm}$ intemal diameter acrylic tube with a porous wall mixer section where water is introduced. The length between the top of the mixer and the inlet of the first extraction unit is $4.2 \mathrm{~m}$, i.e., 440D. The distance necessary to reach an equilibrium condition is given by Kataoka and Ishii (1982) as follows:

$$
Z \approx 440 \mathrm{DWe},{ }^{0.25} / \mathrm{Re}, 0.5
$$

where

$$
W e_{t} \equiv \frac{\rho_{s} j_{s}^{2} D}{\sigma}\left(\frac{\Delta \rho}{\rho_{s}}\right)^{1 / 3}
$$

$$
\operatorname{Re},=\frac{\rho, j_{f} D}{\mu,}
$$

For the present experiment, the value of ZD $<230$ for all cases. Hence, the flow can be regarded as fully developed at the first extraction unit.

The deposition length, measured from the top of the first extraction unit to the top of second extraction unit, is $0.45 \mathrm{~m}$. To assure proper mating of sections the acrylic langes were reamed with a tapered reamer. A schematic of the experimental facility is shown in Figure 1.

\section{Water Flow}

The loop was supplied with demineralized water which was circulated using a $1 / 2 \mathrm{HP}$ pump. The water flow rate was measured using two calibrated rotameters for different flow ranges, and then injected into the mixer. The rotameter for low water flows has a range of $2.53 \times 10^{-7}-1.14 \times 10^{-5} \mathrm{~m}^{3} / \mathrm{s}$ with $\neq 2 \%$ accuracy, and the other one has a range of $7.58 \times 10^{-6}$ $-1.14 \times 10^{-4} \mathrm{~m}^{3} / \mathrm{s}$ with $\pm 3 \%$ accuracy. The calibration of these two rotameters has been checked against the first extraction flow meter. A filter connected to the bypass water loop was used to maintain the circulated water clean.

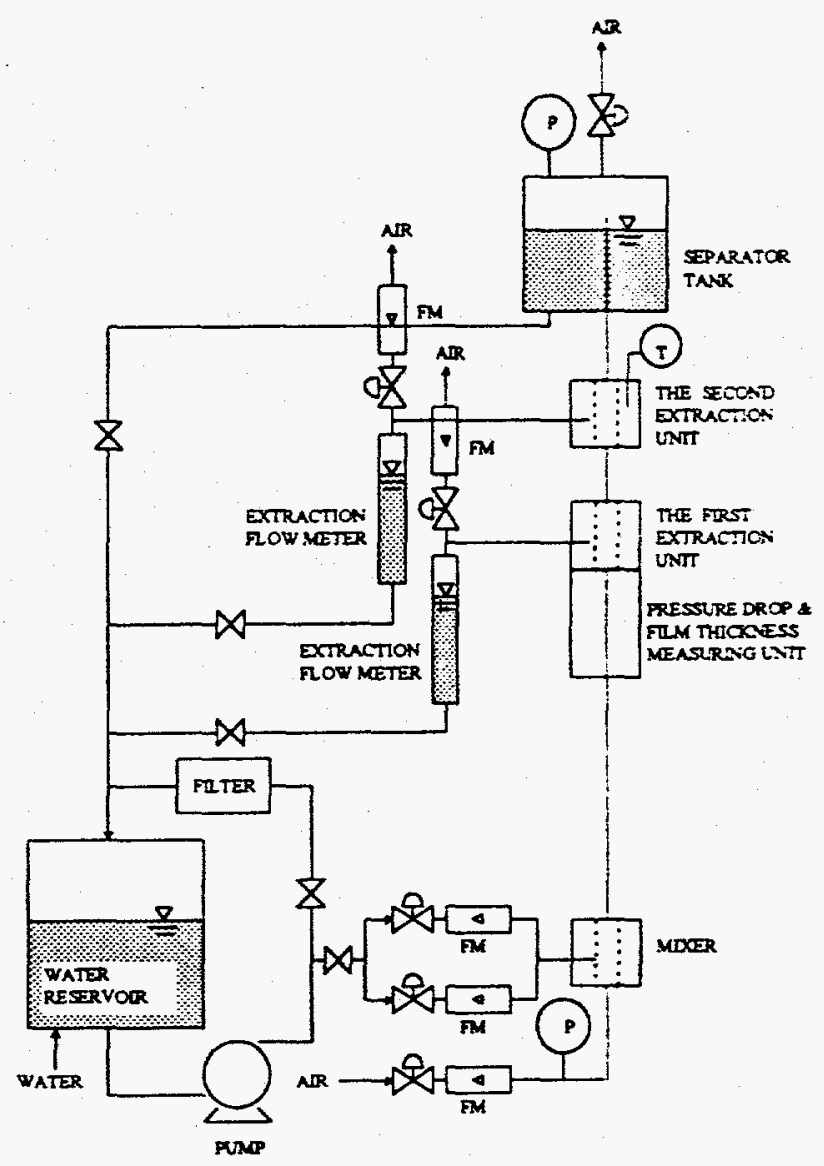

Figure 1 Schematic of Experimental Loop 


\section{Air Flow}

The compressor available at the Purdue Airport Hangar \#3 provided very high air flow rates at $930 \mathrm{kPa}$. A rotameter, with a range of $9.44 \times 10^{-4}-9.44 \times 10^{-3} \mathrm{~m}^{3} / 5$ with $\pm 2 \%$ accuracy, was used to measure the inlet air flow rate. $W_{\mathrm{G}}$. A pressure gauge, with a range of $1-1100 \mathrm{kPa}$ with $\pm 2 \%$ accuracy, was used to measure the inlet air pressure, $P_{n}$. The air pipe was connected to the bottom of the test section. In the mixer, the water was injected into the test section through a $76 \mathrm{~mm}$ long porous wall section with porosity of $100 \mu \mathrm{m}$ and formed a liquid film around the periphery of the tube.

\section{Temperature Measurement}

An Omega DP116 thermocouple, with a range of $0-400$ ${ }^{\circ} \mathrm{C}$ with $\pm 0.8 \%$ accuracy, measured the temperature in the first extraction unit. Since the experiment was conducted at room temperature, the water throughout the loop was assumed to be at the same temperature.

\section{Entrainment Measurement}

As the liquid film goes up with the air flow along the test section, a portion of the liquid is entrained into the gas core. In the first extraction unit, the liquid film was extracted by suction though a porous wall section with a pore size of 100 $\mu \mathrm{m}$. The extracted liquid flow was collected using two calibrated extraction flow meters, one for low flows and the other for high flows. The flow rate, $W_{L E 1}$, gave a measure of the liquid film flow rate, and by inference of the entrainment fraction. The two extraction flow meters were made of $76 \mathrm{~mm}$ and $38 \mathrm{~mm}$ internal diameter tubes approximately $1 \mathrm{~m}$. long. For low water flow, the small diameter flow meter reached steady state more easily than the big diameter flow meter, but for high water flow; the big diameter flow meter was needed to bave enough time to operate the system accurately. Measuring tapes were attached on the wall of the extraction flow meters. An electrical weight scale was used to calibrate the extraction flow meters. The extracted flow rate was measured using a stop watch to record the final time together with the initial and final water levels.

\section{Entrainment Rate Measurement}

The entrained liquid droplets redeposited downstream of the first extraction unit and formed a new liquid film on the wall of the test section. This new liquid film was extracted again in the second extraction unit. The extracted liquid flow was collected in a $38 \mathrm{~mm}$ internal diameter extraction flow meter. The extracted liquid rate, $W_{L 2}$, divided by the deposition area gives a measure of the deposition rate and by inference the entrainment rate. Both the extracted air flow rates from the first and second extraction units were measured using a rotameter which has a range of $2.53 \times 10^{-8}-2.78 \times 10^{-6}$ $\mathrm{m}^{3} / \mathrm{s}$ with $\pm 2 \%$ accuracy.
The remaining mixture of air and entrained liquid droplets downstream of the second extraction unit were discharged to a separator tank. A safety relief valve with a threshold of $690 \mathrm{kPa}$ was connected to the top of the separator tank. A mercury manometer was used to measure the pressure in the separator tank, $P_{\text {sys. The tic marks for the }}$ manometer are $3.2 \mathrm{~mm}(0.125 \mathrm{in})$, so the uncertainty for $P_{s y s}$ are $220 \mathrm{~Pa}$. Because the pressure drop between the first extraction unit to the separator tank is not significant, $P_{s y s}$ can be treated as the pressure at the first extraction unit for the calculations of air density and velocity. The collected water in the separator tank and the extraction flow meters was drained to the water reservoir.

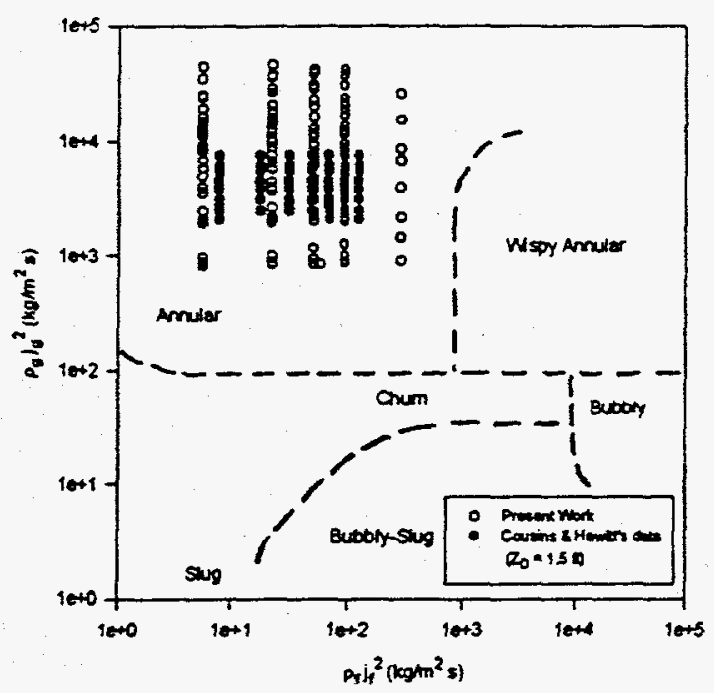

Figure 2 Flow Regime Map with Data Obtained

\subsection{Experimental Ranges}

Cousins and Hewitt (1968) performed experiments with air-water mixture flowing upwards in vertical round tubes and obtained the droplet mass transfer coefficient and the liquid entrainment data. One of the main objectives of the present work is to extend the range of annular air-water flow data to higher flowrates and pressures. There are 121 data points obtained with the experimental loop. A flow regime map with Cousins and Hewitt's (1968) data and the data obtained for the present work is shown in Figure 2 . The range of experimental data was extended on both air flow and water flow. The range of $\rho_{\mathrm{r}} \mathrm{jr}^{2}$ is 5.5 to $289 \mathrm{~kg} / \mathrm{ms}^{2}$ and the range of $\rho_{g} j_{g}{ }_{g}$ is 480 to $45000 \mathrm{~kg} / \mathrm{ms}^{2}$. There are no published data for water or air flow rates this high so this is a new contribution. The experiments were conducted at four different pressures, i.e., $140 \mathrm{kPa}, 240 \mathrm{kPa}, 380 \mathrm{kPa}$ and $660 \mathrm{kPa}$. These experiments cover the range from about one atmosphere to six

Separator Tank 
atmospheres so we can capture the pressure effect. All measurement ranges are listed in Table 1.

Table 1 Range of Parameters

\begin{tabular}{|c|c|c|}
\hline Parameter & Unit & Range \\
\hline Air Flow Range & $\mathrm{kg} / \mathrm{s}$ & $0.0028-0.028$ \\
$\begin{array}{c}\text { Water Flow Rate } \\
\text { at the injection }\end{array}$ & $\mathrm{kg} / \mathrm{s}$ & $0.0053-0.038$ \\
$\mathrm{j}_{\mathrm{f}}$ & $\mathrm{m} / \mathrm{s}$ & $0.074-0.54$ \\
$j_{\mathrm{g}}$ & $\mathrm{m} / \mathrm{s}$ & $24.5-126$ \\
Pressure & $\mathrm{kPa}$ & $140-660$ \\
\hline
\end{tabular}

\subsection{Entrainment Measurement}

The water injected into the test section forms a liquid film around the periphery of the tube. As the liquid film flows up the tube, part of the liquid film is entrained as fine droplets in the gas core. When the fully developed flow is established, the entrainment rate is equal to the deposition rate and the entrainment fraction reaches its asymptotic value. Since the length between the top of the mixer to the inlet of the first extraction unit is about 440 diameters, fully developed annular flow is expected.

The entrainment, $E$, can be calculated from the following expression:

$$
E=1-\frac{W_{L F_{1}}}{W_{L}}
$$

It was found that the liquid film could not be extracted without also removing some of the core vapor stream. For low water flow, either visualization or a plot of extracted liquid flow vs. extracted air flow can be used to ensure all the liquid flow had been removed. To monitor the liquid film extraction, the flow immediately downstream of the extraction probe may be visually observed. When the extracted air flow was increased, the liquid film downstream of the extraction unit decreased. When the extracted air flow increased further, a dramatic change of the flow regime in the visualization section was seen. The tube turned from opaque to transparent. After that, no matter how much more air flow was extracted, no difference of the flow regime was observed. It is assumed that the liquid film was extracted completely at that point.

But for high water flows, it was hard to tell when the liquid film was extracted completely by visualization. A plot of extracted liquid flow vs. extracted air flow was needed to determine when all the liquid film was extracted. Two samples are shown in Figure 3 for low and high water flows. For a certain inlet condition, the extracted liquid flow reaches a plateau beyond a certain value of the extracted air flow. The higher the inlet water flow, the greater percentage of the inlet air flow that needs to be extracted to reach the plateau. Once on the plateau is reached it is assumed that the liquid film is extracted completely.

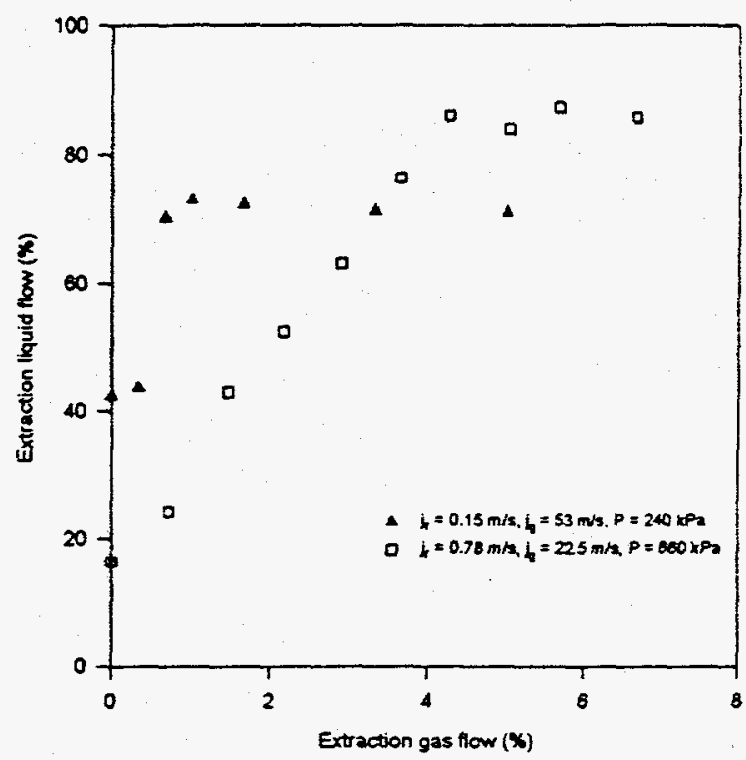

Figure 3 Extraction Liquid Flow vs. Extraction Gas Flow

The amount of extracted gas was always the minimum necessary to remove the liquid film. Furthermore the pressure drop across the tube was minimized to minimize the gas extraction. This was achieved with a pore size of $100 \mu \mathrm{m}$ after comparing measurement with $20 \mu \mathrm{m}, 40 \mu \mathrm{m}$ and $100 \mu \mathrm{m}$ porous tubes.

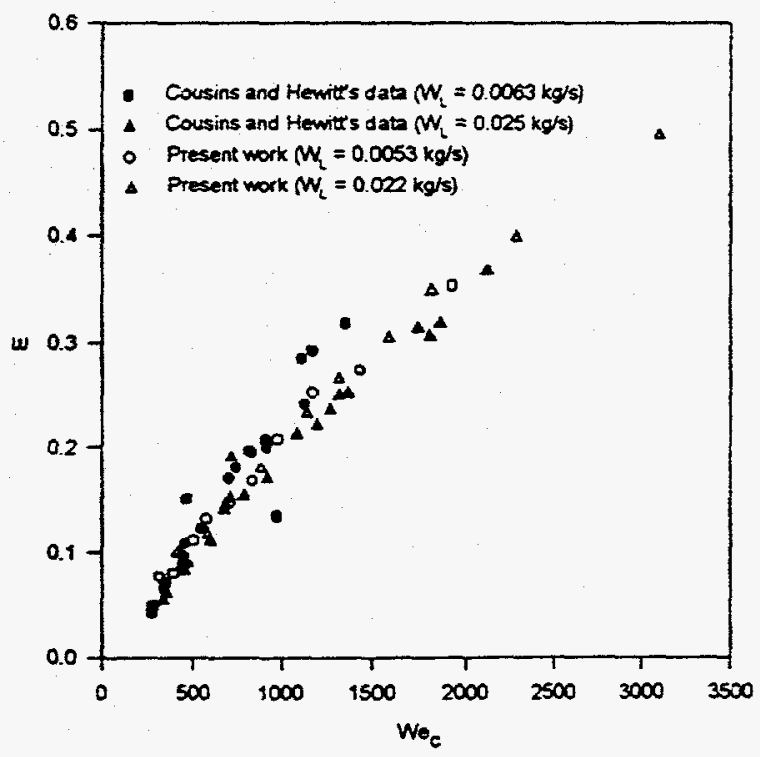

Figure 4 Comparison of Replicated Experimental Data with Cousins and Hewitt's Data 
On the average the extracted gas was only $1.5 \%$ of the total gas flow. The worst case was $6.3 \%$. Therefore the error induced by the gas extraction is small.

A set of the data of Cousins and Hewitt (1968) and the replicated experimental results in our test loop are compared on the plot shown in Figure 4 and the agreement is good.

\subsection{Entrainment Rate Measurement}

Downstream of the first extraction unit, the entrained liquid droplets in the gas core deposit on the walls to forms a new liquid film. The deposition rate was measured with the second extraction flow meter. Assuming the deposition rate and the entrainment rate are equal for fully developed flow, the entrainment rate may be thus obtained.

The deposition rate and the entrainment rate can be calculated from the following equation:

$$
\dot{\varepsilon} \cong \dot{d} \cong \frac{W_{L_{2}}}{\pi D Z_{D}}
$$

where $Z_{D}$ is the deposition length.

A set of Cousins and Hewitt's (1968) experimental data were reproduced for testing the performance of the second extraction unit. A comparison of $W_{L F 2}$ vs. $W_{G}$ with Cousins and Hewitt's data - Figure 5 - shows that the agreement is good. Note that the deposition length is $0.46 \mathrm{~m}$ for the set of Cousins and Hewitt's data, and $0.45 \mathrm{~m}$ for the present work.

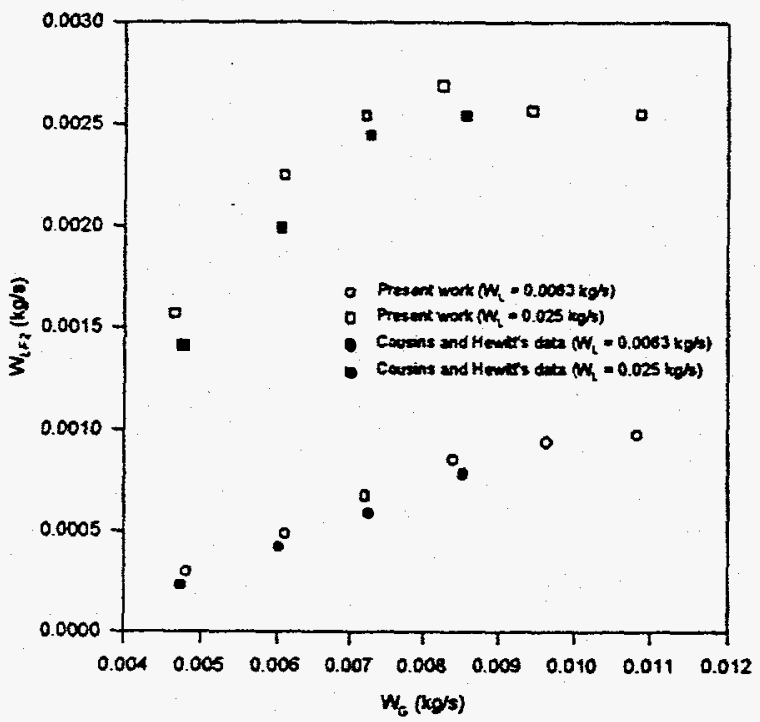

Figure 5 Comparison of $\mathrm{W}_{\mathrm{LF} 2}$ Data with Cousins and Hewitt's Data
Table 2 Uncertainties

\begin{tabular}{|c|c|c|c|}
\hline & $\frac{\Delta \mathrm{Re}_{y}}{\mathrm{Re}_{\sharp}}$ & $\frac{\Delta W e_{c}}{W e_{c}}$ & $\frac{\Delta \dot{\varepsilon}}{\dot{\varepsilon}}$ \\
\hline Worst case & $12.8 \%$ & $17.3 \%$ & $13.9 \%$ \\
\hline Average & $6.1 \%$ & $5.0 \%$ & $2.6 \%$ \\
\hline
\end{tabular}

\subsection{Experimental Error Analysis}

Because of the limitations of the measuring instruments and operating skill, experimental data inevitably have uncertainties. So, an uncertainty analysis or error analysis is provided for data quality assessment.

Based on a propagation of uncertainty analysis, the uncertainty for several variables were calculated and tabulated in Table 2.

\section{Analysis}

There are several entrainment rate correlations available in the literature. Here we describe and compare the correlating methods of 1) Dallman et. al. (1979) ,2) Kataoka and Ishii (1982) and 3) a new dimensionless group based on Taylor's ripple instability.

\section{Dallman's (1979) Entrainment Rate Correlation}

Dallman, Jones and Hanratty (1979) correlated the entrainment rate from a liquid film with the following equation, provided the gas velocity, $u_{\mathrm{g}}$, is not too close to the critical velocity for the onset of entrainment and provided that the mass flow rate of the liquid film, $W_{L F}$, is small enough that the dependence of $\dot{\varepsilon}$ on $\mathrm{W}_{\mathrm{LF}}$ is linear:

$$
\dot{\varepsilon}=k_{1}\left(\frac{W_{L}-W_{L E C}}{P}\right) u_{s}^{2} \rho_{s}^{1 / 2} \rho_{s}^{1 / 2}
$$

where $k_{A}$ is an entrainment coefficient, $P$ is the perimeter of the wetted surface and $W_{\text {LFC }}$ is the critical liquid mass flow rate required for the onset of entrainment. For air-water up flow, they proposed $\mathrm{k}_{\mathrm{A}}=3.5 \times 10^{-6} \mathrm{~s}^{2} / \mathrm{kg}$ and $\mathrm{W}_{\mathrm{LPC}} / \mathrm{P}=0.046$ $\mathrm{kg} / \mathrm{ms}$. To apply equation $(6)$, we assume $\mathrm{u}_{\mathrm{g}} \approx \mathrm{j}_{\mathrm{g}}$. 


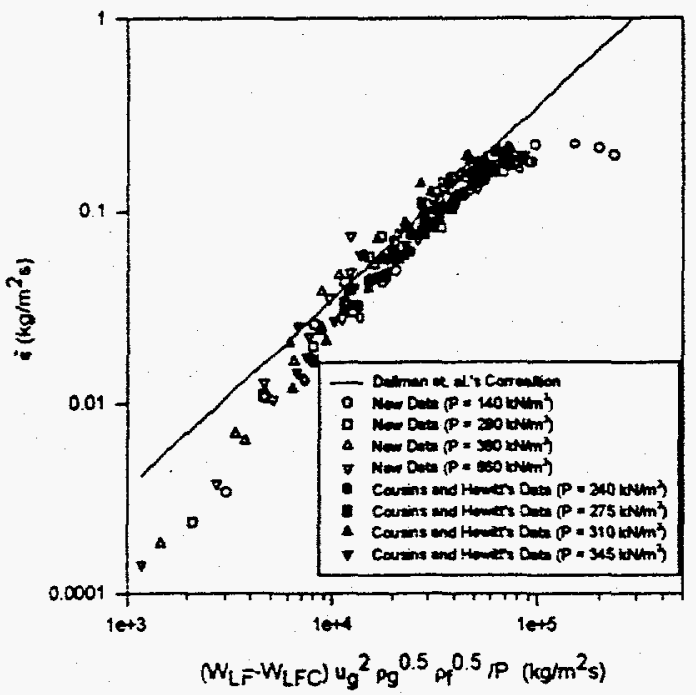

Figure 6 Comparison of Dallman et al.'s Correlation with Cousins and Hewitt's Data and New Data

Figure 6 shows the comparison of the entrainment rate correlation of Dallman et al. with Cousins and Hewitt's data and the new data. It shows that Dallman's correlation is able to collapse the low water flow rate data well.

Kataoka and Ishii's (1982) Entrainment Rate Correlation

Kataoka and Ishii (1982) started with Paleev and Filippovich's (1966) correlation for the deposition coefficient and developed a model for entrainment rate based on a force balance at the gas-liquid wavy interface. The final form of Kataoka and Ishii's correlation is defined for two different regimes: under-entrained or developing entrainment, and overentrained or fully developed entrainment.

The developing entrainment region is defined by

$$
\frac{E}{E_{0}} \leq 1
$$

where

$$
E_{.}=\tanh \left(7.25 \times 10^{-7} W e_{f}^{1.25} \operatorname{Re}_{f}^{0.25}\right)
$$

For this region the entrainment rate is given by

$$
\begin{aligned}
& \frac{\dot{\varepsilon} D}{\mu_{f}}=0.72 \times 10^{-9} \operatorname{Re}_{f}^{1.75} W_{e_{1}}\left(1-E_{0}\right)^{0.25}\left(1-\frac{E}{E_{0}}\right)^{2} \\
& +6.67 \times 10^{-7}\left(\operatorname{Re}, W_{e_{f}}\right)^{0.05}\left(\frac{\mu_{\varepsilon}}{\mu_{f}}\right)^{0.26}(1-E)^{0.105}
\end{aligned}
$$

The fully developed or over-entrained region is defined by

$$
\frac{E}{E}>1
$$

For this region the entrainment rate becomes

$$
\frac{\dot{\varepsilon} D}{\mu_{j}}=6.67 \times 10^{-7}\left(\operatorname{Re}_{f} W e_{l}\right)^{0.505}\left(\frac{\mu_{l}}{\mu_{f}}\right)^{0.26}(1-E)^{0.10}
$$

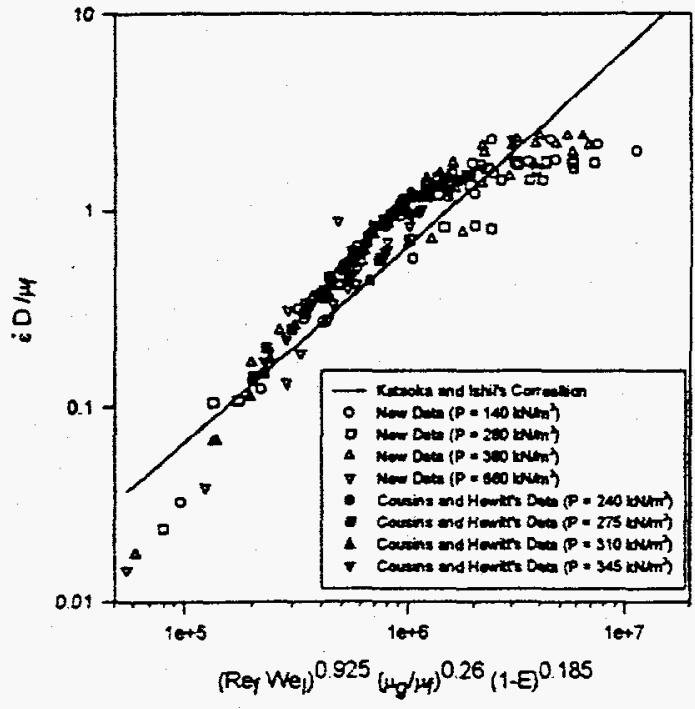

Figure 7 Comparison of Kataoka and Ishii's Correlation with Cousins and Hewitt's Data and New Data

Figure 7 shows the comparison of the entrainment rate correlation of Kataoka and Ishii with the Cousins and Hewitt's data and the new data. It shows that the proposed dimensionless group $\left(\operatorname{Re}_{i} \mathrm{We}_{1}\right)^{0.925}\left(\mu_{\mathrm{s}} / \mu_{\ell}\right)^{0.26}(\mathrm{l}-\mathrm{E})^{0.185}$ collapses the data very well for the low entrainment rate data, but there is some scatter as the entrainment rate becomes larger.

Entrainment Rate Model Based on Taylor's Ripple Instabiliti

The model of Taylor (1956) for growth of ripples was applied to obtain a correlation for entrainment rate. The model is based on linear stability theory so it is not expected to produce an exact correlation, however it results in the same non-dimensional groups that were used previously by Kataoka and Ishii (1982). Taylor proposes that the perturbations on the liquid-gas interface may be modeled as:

$$
\eta=\eta_{0} e^{j+a x+a z}
$$

which may be rewritten as:

$$
\eta=\eta_{0} e^{\nu x+\ln (\infty)} e^{R(\infty x)}
$$

Then the rate of growth of the ripples is the Lagrangian derivative taken at the wave speed:

$$
\frac{D_{c} \eta}{D t}=\eta_{0} e^{2 \alpha+\operatorname{lom}(\alpha t)} e^{\lambda(\alpha t)} R(\alpha)=\eta R(\alpha)
$$

The entrainment rate is proportional to the liquid density multiplied by the average growth rate of the ripples:

$$
\dot{\varepsilon} \propto \dot{\rho}, \bar{\eta} R(\alpha)
$$


According to Taylor's analysis:

$$
\begin{gathered}
R(\alpha)=2 \kappa_{0} \kappa_{0} \sqrt{\frac{\rho_{s}}{\rho_{f}}}\left(\frac{s}{x^{2} \theta^{k}}\right) \\
\text { where } \kappa_{0}=\frac{\rho_{g} u_{g}^{2}}{\sigma}
\end{gathered}
$$

and the quantity $\frac{s}{x^{2} \theta^{3 / 2}}$ has an asymptotic value equal to 0.192 for low viscosity fluids such as the water film in the present case. However it may not be constant for very viscous fluids. Then combining equations (15) through (17):

$$
\frac{\dot{\varepsilon} D}{\mu_{f}}=\frac{\rho_{s} u_{s}^{2} D}{\sigma} \frac{\rho_{f} u_{s} \bar{\eta}}{\mu_{f}} \sqrt{\frac{\rho_{s}}{\rho_{f}}}
$$

According to Henstock and Hanratty (1976) for a turbulent liquid film in annular flow:

$$
\frac{m u}{v_{j}}=0.0379\left(\frac{4 m u}{v_{f}}\right)^{0.9}
$$

where $\mathrm{m}$ is the film thickness. Then,

$$
\frac{u_{f}^{*}}{u_{f}}=\sqrt{\frac{0.0014}{\operatorname{Re}_{y}^{0.2}}}=\sqrt{c_{f w}}
$$

where $c_{f w}$ is the wall coefficient of friction. A similar definition may be used for the interfacial coefficient. Then inserting (20) into (18) yields:

$$
\frac{\dot{\varepsilon} D}{\mu_{j}} \propto W e_{c} \operatorname{Re}_{y} \frac{\bar{\eta}}{m} \sqrt{\frac{c_{f f}}{c_{\rho_{w}}}}
$$

This is similar to the dimensionless correlation proposed by Kataoka and Ishii except for the term $\frac{\bar{\eta}}{m} \sqrt{\frac{c_{g}}{c_{m}}}$ and the absence of the viscosity ratio. The later is a consequence of neglecting viscous effects in the gas phase. One further argument is now proposed: Taylor did not account for the inertia of the droplets in the gas stream but in annular mist flow their effect may be significant, so the homogeneous density of the gas droplet mixture will be used instead of the gas density in equation (21), i.e., $\rho_{c}=\frac{W_{G}+W_{L E}}{W_{G}} \rho_{s}$.

where $W_{L E}$ is the mass flow rate of the entrained liquid.

This derivation based on Taylor's theory may be viewed as a scaling analysis: it indicates the relevant dimensionless numbers.

Hence a modification to Kataoka and Ishii's correlation is proposed:

$$
\frac{\dot{\delta} D}{\mu_{f}}=k\left[W_{e} \cdot\left(\frac{\partial_{\rho}}{\rho_{k}}\right)^{g}(\operatorname{Re},-\operatorname{Re} k)\right]^{0.02 s}\left(\frac{\mu_{s}}{\mu_{j}}\right)^{0.26}
$$

where

$$
\begin{gathered}
\text { We, } \equiv \frac{\rho_{c} j_{e}^{2} D}{\sigma}, \\
\operatorname{Re},=\frac{\rho_{f} j_{f} D}{\mu_{f}}(1-E)=\frac{4 \rho_{f} u_{f} m}{\mu_{f}},
\end{gathered}
$$

$k$ is a constant, and $R_{e s c}$ is the critical film Reynolds number.

There are several correlations for $R_{i v c}$ in the published literature. A summary of these correlations was given by Owen (1986). Owien applied Azzopardi's correlation to calculate Rete for pressures of $240 \mathrm{kPa}$ and $377 \mathrm{kPa}$, respectively. The corresponding values of $\mathrm{Re}_{\mathrm{ic}}$ were calculated as 82 and 78 .

In the correlation we have assumed $\frac{\bar{\eta}}{m}$ is constant. This assumption, which does not seem to have a significant effect on the scaling of the data, is similar to the assumption made by Wallis (1969) in his interfacial shear correlation.

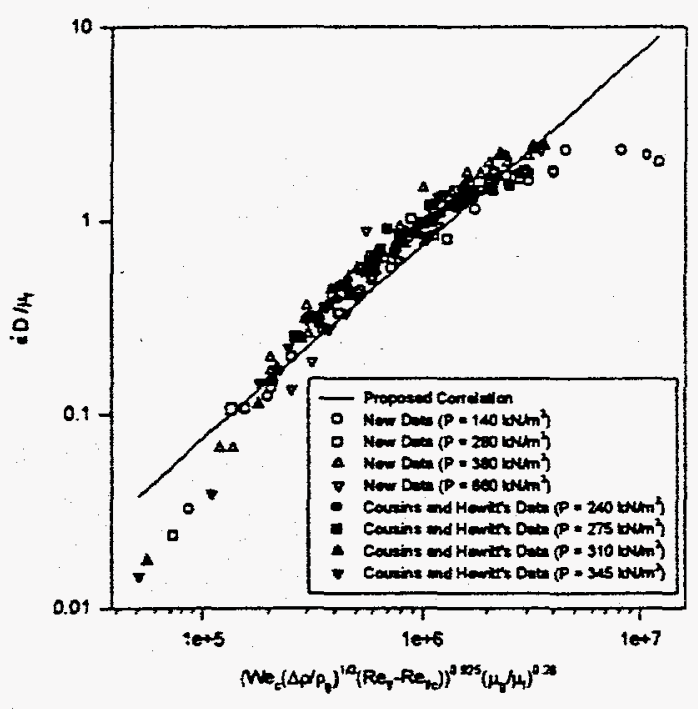

Figure 8 Comparison of Proposed Correlation with Cousins and Hewitt's Data and New Data

Furthermore we have neglected the factor $\sqrt{\frac{c_{s}}{c_{s w}}}$ primarily because there is no reliable correlation for $c_{6}$ at the present time. Figure 8 shows the plot of Cousins and Hewitt's data and the new data against the proposed correlation. Assuming $R_{\text {ext }}=80$, a least squares fit to the data gives $k=$ $7.42 \times 10^{-7}$. The proposed dimensionless correlation collapses the data well, but for $\varepsilon D / \mu_{\mathrm{f}}>1$, the relationship seems to be 
no longer linear. This shows one limitation for the proposed correlation

Comparing Cousins and Hewitt's data and the new, the standard deviations of Kataoka and Ishii's correlation, Dallman et. al.'s correlation and the new correlation are listed in Table 3.

Table 3 Standard Deviations of Entrainment Rate Correlations

\begin{tabular}{|c|c|c|c|}
\hline & Katzoka and Lhii & Dallman et al. & $\begin{array}{c}\text { Proposed } \\
\text { correlation }\end{array}$ \\
\hline $\begin{array}{c}\text { Cousins and } \\
\text { Hewit's dats } \\
\left(Z_{D}=1.5 \mathrm{~A}\right) \\
(64 \mathrm{pts})\end{array}$ & $34.9 \%$ & $31.8 \%$ & $22.2 \%$ \\
\hline $\begin{array}{c}\text { New dats } \\
(121 \mathrm{pts})\end{array}$ & $47.2 \%$ & $64.4 \%$ & $34.4 \%$ \\
\hline
\end{tabular}

\section{Conclusions}

The entrainment rate correlation of Kataoka and Ishii has been modified based on a model for ripple growth and new data. Even though the proposed correlation has the advantage of being calibrated with the new data, the correlations of Kataoka and Ishii and Dallman et. al. also compared well to the new data. The progress of the present work is that it is dimensionless and more mechanistic, therefore it can be expected to be used more flexibly and can be improved if the underlying models are perfected.

Furthermore the proposed correlation should be valid for the new data range as well as the data correlated by Kataoka and Ishii. The present work was for higher gas velocities than previous experiments and it was found that for high $\mathrm{We}_{\mathrm{c}}$ the existing correlations fail to give reasonable predictions. For this region, the application of the existing correlations may not be satisfactory.

\section{References}

1. Andreussi, P., et. al., "Analysis of droplet motion in annular gas-liquid flow," Paper No. 106e, AlChE Annual Meeting, Los Angeles, CA, November 1982.

2. Asali, J. C., Hanratty, T. J. and Andreussi, P., "Interfacial Drag and Film Height for Vertical Annular Flow," AlChE Journal, Vol. 31, No. 6, 895-902, 1985

3. Azzopardi, B. J., "Droplet sizes in annular two-phase flow," Experiments in Fluids, 3:53-59, 1985.

4. Azzopardi, B. J., Piearcey, A. and Jepson, D. M., "Drop size measurements for annular two-phase flow in $20 \mathrm{~mm}$ diameter vertical tube," Experiments in Fluids, 11:191197, 1991.
5. Cousins, L. B. and Hewitt, G. F., "Liquid Phase Mass Transfer in Annular Two-Phase Flow: Droplet Deposition and Liquid Entrainment," UKAEA Report AERE-R5657, 1968.

6. Dallman, J. C., Jones, B. G., and Hanratty, T J., "Interpretation of Entrainment Measurements in Annular Gas-Liquid Flows," Two-Phase Momentum, Heat and Mass Transfer in Chemical, Process and Energ. Engineering System, Vol. 2, 681-693, Hemisphere, Washington, D.C., 1979.

7. Dallman, J. C., Laurinat, J. E. and Hanratty, T. J., "Entrainment for Horizontal Annular Gas-Liquid Flow," Intl. J. Multiphase Flow, Vol. 10, No. 6, 677-690, 1984.

8. Govan, A. H. et. al., "Wall shear-stress measurements in vertical air-water annular two-phase flow," Int. J. Multiphase Flow, 15:3:307-325, 1989

9. Henstock, W. H. and Hanratty, T. J., "The Interfacial Drag and Height of the Wall Layer in Annular Flows," AIChE Jourmal, Vol.22, No. 6, 990-1000, 1976.

10. Ishii, M. and Mishima, K., "Correlation for Liquid Entrainment in Annular Two-phase Flow of Low Viscous Fluid." Argonne National Laboratory Report, ANL/RAS/LWR 81-2, 1981.

11. Kataoka, I. and Ishii, M. (1982) "Mechanism and Correlation of Droplet Entrainment and Deposition in Annular Two-Phase Flow, "NUREG/CR-2885, ANL-8244, 1982.

12. Keeys, R. K. F., Ralph, J. C. and Roberts, D. N., "The Effect of heat flux on liquid entrainment in stream-water flow in a vertical tube at 1000 psia," AERE-R-6294, Harwell Laboratories, 1970.

13. Keeys, R. K. F., Ralph, J. C. and Roberts, D. N., "Liquid entrainment in adiabatic stream water flow at 500 and 1000 psia," AERE-R-6293.

14. Okada, O. and Fujita, H., "Behavior of liquid films and droplets in the non-equilibrium region of a downward annular mist flow (comparison of porous and central nozzle mixing methods)," Int. J. Multiphase Flow, 19:1:79-89, 1993.

15. Owen, D. G., "An Experimental and Theoretical Analysis of Equilibrium Annular Flows, " Ph. D. Thesis, University of Birmingham, 1986.

16. Paleev, I. I. and Filippovich, B. S., "Phenomena of Liquid Transfer in Two-Phase Dispersed Annular Flow, "Intl. J. Heat and Mass Transfer, Vol. 9, 1089-1093, 1966.

17. Sekoguchi, K., Tanaka, O and Ueno, T., "On the determination method of entrained droplet flow rate in the disturbance wave region of annular tlow," Bulletin of JSME, 28:240:1105-1112, 1985.

18. Taylor, G. I., "Generation of Ripples by Wind Blowing over a Viscous Fluid," The Scientific Papers of Sir G. I. Taylor, Vol. III, 244-254, Cambridge University Press. 1963.

19. Wallis, G. B., "One Dimensional Two Phase Flow," McGraw-Hill, 1969 


\section{DISCLAIMER}

This report was prepared as an account of work sponsored by an agency of the United States Government. Neither the United States Government nor any agency thereof, nor any of their employees, makes any warranty, express or implied, or assumes any legal liability or responsibility for the accuracy, completeness, or usefulness of any information, apparatus, product, or process disclosed, or represents that its use would not infringe privately owned rights. Reference herein to any specific commercial product, process, or service by trade name, trademark, manufacturer, or otherwise does not necessarily constitute or imply its endorsement, recommendation, or favoring by the United States Government or any agency thereof. The views and opinions of authors expressed herein do not necessarily state or reflect those of the United States Government or any agency thereof. 